\title{
Monitoring the mean vector and the covariance matrix of multivariate processes with sample means and sample ranges
}

\author{
Antônio Fernando Branco Costa,*, Marcela Aparecida Guerreiro Machado ${ }^{\mathrm{b}}$ \\ a,*fbranco@feg.unesp.br, UNESP, Brasil \\ ${ }^{\mathrm{b}}$ marcela@feg.unesp.br, UNESP, Brasil
}

\begin{abstract}
The joint $\overline{\mathrm{X}}$ and $R$ charts and the joint $\overline{\mathrm{X}}$ and $\mathrm{S}^{2}$ charts are the most common charts used for monitoring the process mean and dispersion. With the usual sample sizes of 4 and 5 , the joint $\bar{X}$ and $R$ charts are slightly inferior to the joint $\overline{\mathrm{X}}$ and $\mathrm{S}^{2}$ charts in terms of efficiency in detecting process shifts. In this article, we show that for the multivariate case, the charts based on the standardized sample means and sample ranges (MRMAX chart) or on the standardized sample means and sample variances (MVMAX chart) are similar in terms of efficiency in detecting shifts in the mean vector and/or in the covariance matrix. User's familiarity with the computation of sample ranges is a point in favor of the MRMAX chart. An example is presented to illustrate the application of the proposed chart.
\end{abstract}

Keywords

Control charts. Mean vector. Covariance matrix. Multivariate processes.

\section{Introduction}

The control of several parameters is a requirement to assure the quality of many processes nowadays. Hotelling (1947) provided the first solution to this problem by suggesting the use of the $\mathrm{T}^{2}$ statistic for monitoring the mean vector of multivariate processes. Many innovations have been proposed to improve the performance of the $\mathrm{T}^{2}$ charts. Costa and Machado (2007) studied the properties of the synthetic $\mathrm{T}^{2}$ chart with two-stage sampling. Machado and Costa (2008b) considered the use of simultaneous $\bar{X}$ charts as an alternative to the use of the $\mathrm{T}^{2}$ chart. Costa and Machado (2008b) considered the use of the double sampling procedure with the chart proposed by Hotelling.

The first multivariate control chart for monitoring the covariance matrix $\boldsymbol{\Sigma}$ was based on the charting statistic obtained from the generalized likelihood ratio test. For the case of two variables, Alt (1985) proposed the generalized variance statistic $|\mathrm{S}|$ to control the covariance matrix $\boldsymbol{\Sigma}$.

Control charts more efficient than the $|\mathrm{S}|$ chart have been proposed. Recently, Costa and Machado (2008a, 2009), Machado and Costa (2008a) and Machado, De Magalhães and Costa (2008), Machado, Costa and Rahim (2008), Machado, Costa and Claro (2009) considered the VMAX statistic to control the covariance matrix of multivariate processes. The points plotted on the VMAX chart correspond to the maximum of the sample variances of the $p$ quality characteristics.

There are a few recent papers dealing with the joint control of the mean vector and the covariance matrix of multivariate processes. Chou et al. (2002) have considered the multivariate control chart for monitoring the process mean vector and covariance matrix for the related quality characteristics simultaneously by using log-likelihood ratio statistics. Takemoto and Arizono (2005) considered the multivariate $(\bar{X}, S)$ control chart for monitoring the mean vector $\mu$ and the covariance matrix $\Sigma$ simultaneously based on the Kullback-Leibler information as the test statistic.

Khoo (2005) proposed a control chart based on the $\mathrm{T}^{2}$ and $|\mathrm{S}|$ statistics for monitoring bivariate 
processes. The speed with which the chart signals changes in the mean vector and/or in the covariance matrix was obtained by simulation. The results are not compelling, once the proposed chart is slow in signaling out-of-control conditions. Chen, Cheng and Xie (2005) proposed a single EWMA chart to control both, the mean vector and the covariance matrix. Their chart is more efficient than the joint $\mathrm{T}^{2}$ and $|\mathrm{S}|$ in signaling small changes in the process. Zhang and Chang (2008) proposed two EWMA charts based on individual observations that are not only fast in signaling but also very efficient in informing which parameter was affected by the assignable cause; if only the mean vector or only the covariance matrix or both.

Machado, Costa and Marins (2009) proposed two new control charts for monitoring the mean vector and the covariance matrix of bivariate processes. First, they proposed the MVMAX chart, which only requires the computation of statistics familiar to the users, that is, sample means and sample variances. Second, they proposed the joint use of two charts based on the non-central chi-square statistic (NCS statistic), named as the NCS charts. The joint NCS charts are recommended for those who aim to identify the out-of-control variable instead of the nature of the disturbance, that is, the one that only affects the mean vector or only affects the covariance matrix or both.

For the univariate case, the joint $\overline{\mathrm{X}}$ and $R$ charts are commonly used for monitoring process mean and variance. According to the literature, a control chart based on sample means and sample ranges has not yet been proposed for monitoring the mean vector and the covariance matrix of multivariate processes.

As an alternative to the MVMAX chart, we propose a chart based on the synthetic procedure, named as the synthetic MRMAX chart, to control both the mean vector and the covariance matrix of multivariate processes. The sample points correspond to the maximum among the values of the standardized sample means (in module) and ranges (weighted) of $p$ quality characteristics. The sample points plotted on the MVMAX chart correspond to the maximum among the values of sample means and sample variances. User's familiarity with sample means and sample ranges is a point in favor of the MRMAX chart.

The paper is organized as follows. In section 2 we compare the efficiency of the joint $\overline{\mathrm{X}}$ and $R$ charts and $\bar{X}$ and $S^{2}$ charts. In Section 3 we present the properties of the synthetic MRMAX chart. We also present its competitors, that is, the synthetic MVMAX chart and the joint $\mathrm{T}^{2}$ and $|\mathrm{S}|$ charts. The proposed chart is compared with its competitors in Section 4. In Section 5, an example is presented to illustrate the application of the proposed chart. Conclusions are in Section 6.

\section{Univariate charts for monitoring process mean and dispersion}

In recent years, considerable attention has been devoted to the joint monitoring of the process parameters $\mu$ and $\sigma$. The $\bar{X}$ chart is used for monitoring the parameter $\mu$ and the $R$ or the $S^{2}$ charts are used for monitoring the parameter $\sigma$. For monitoring both process mean and dispersion, the $R$ chart combined with the $\bar{X}$ chart has been more used than the $S^{2}$ chart. The reason for this fact is that sample ranges are easier to compute. The joint $\overline{\mathrm{X}}$ and $R$ charts and $\overline{\mathrm{X}}$ and $\mathrm{S}^{2}$ charts are briefly discussed in Section 2.1. In Section 2.2 the joint charts are compared in terms of their efficiency in detecting process shifts.

In this paper the average run length $(A R L)$ measures the efficiency of a control chart in detecting a process change. During the in-control period the $A R L=1 / \alpha$ and is called $A R L_{0}$, and during the out-of-control period the $A R L=1 /(1-\beta)$. The risks $\alpha$ and $\beta$ are, respectively, the well-known Type 1 and Type 11 errors. A chart with a larger in-control $A R L\left(A R L_{0}\right)$ indicates lower false alarm rate than other charts. A chart with a smaller out-of-control $A R L$ indicates a better ability of detecting process shifts than other charts.

\subsection{The joint charts}

Let $\mathrm{X}_{1}, \mathrm{X}_{2}, \ldots, \mathrm{X}_{n}$ be a random sample of size $n$ from a normally distributed process with mean $\mu$ and variance $\sigma^{2}$. The process is considered to start in a state of statistical control with the mean and the variance equal to $\mu_{0}$ and $\sigma^{2}{ }_{0}$ respectively. The occurrence of the assignable cause changes the mean from $\mu_{0}$ to $\mu_{1}=\mu_{0}+\delta \sigma_{0}$ and/or the variance from $\sigma_{0}^{2}$ to $\sigma^{2}{ }_{1}=\mathrm{a}^{2} \sigma^{2}{ }_{0}$, with $\delta \neq 0$ and a $>1.0$.

The upper and lower control limits for the $\bar{X}$ chart are respectively

$U C L_{\bar{X}}=\mu_{0}+k_{1} \sigma_{0} / n^{1 / 2}$

$L C L_{\bar{X}}=\mu_{0}-k_{1} \sigma_{0} / n^{1 / 2}$

where $k_{1}$ is the control limit coefficient of the $\bar{X}$ chart. The upper control limit for the $R$ chart is

$U C L_{R}=k_{2} \sigma_{0}$

where $\mathrm{k}_{2}$ is the control limit coefficient of the $R$ chart. We make the lower control limit of the $R$ chart equals to zero for convenience. The control limit for the $\mathrm{S}^{2}$ chart is

$C L=\frac{\sigma_{0}^{2}}{n-1} \chi_{n-1, \alpha}^{2}$ 
The joint charts have probability $P$ of signaling:

$P=P_{M}+P_{D}-P_{M} P_{D}$

Then, the $A R L=1 / P$.

The probability $\mathrm{P}_{\mathrm{M}}$ of $\overline{\mathrm{X}}$ exceeding the upper or the lower control limits is given by:

$$
P_{M}=\Phi\left(-k_{1} / a-\delta n^{1 / 2} / a\right)+\Phi\left(-k_{1} / a+\delta n^{1 / 2} / a\right)
$$

where $\Phi()$ is the cumulative standard normal distribution.

If the $R$ chart is used to control the process dispersion, then the probability $\mathrm{P}_{\mathrm{D}}$ of $R$ exceeding the upper control limit is given by

$P_{D}=1-F_{w}\left(k_{2} / a\right)$

being $F_{w}()$ the accumulated distribution function of the random variable $W=R / \sigma . F_{w}()$ has been tabulated, see Costa, Epprecht and Carpinetti (2005).

If the $S^{2}$ chart is used to control the process dispersion, then the probability $\mathrm{P}_{\mathrm{D}}$ of $\mathrm{S}^{2}$ exceeding the control limit is given by

$P_{D}=1-\operatorname{Pr}\left[\chi_{n-1}^{2}>\frac{\chi_{n-1, \alpha}^{2}}{a^{2}}\right]$

\subsection{Comparing the joint charts}

In this section we compare the joint $\bar{X}$ and $R$ charts with the joint $\bar{X}$ and $S^{2}$ charts. Table 1 shows their ARLS. The joint $\overline{\mathrm{X}}$ and $\mathrm{S}^{2}$ charts are faster than the joint $\overline{\mathrm{X}}$ and $R$ charts in detecting increases in the variance followed or not by shifts in the process mean. The superiority of the joint $\bar{X}$ and $S^{2}$ charts becomes more evident when the process variance is subject to large increases, see the $P V$ values in Table 1 , which are given by:

$$
P v=100 \% \frac{\left(A R L_{\bar{X} R}-A R L_{\bar{X} S^{2}}\right)}{A R L_{\bar{X} R}}
$$

We adopt a Type 1 error of five per one thousand $(\alpha=0.005)$, that is, $A R L_{0}=200.0$. The study with $n>5$ led to larger values of $P V$. According to expression (6), the power of the $\bar{X}$ chart is independent of the shift direction, that is, if the process mean increases or decreases. Based on that, the values of $\delta$ in Table 1 and, in all other tables, are in module.

\section{Multivariate charts for monitoring process mean and dispersion}

\subsection{The MRMAX chart}

In this section we propose a new chart based on sample means and sample ranges for monitoring the mean vector $\mu$ and/or the covariance matrix $\Sigma$ of multivariate processes with $p$ quality characteristics that follow a multivariate normal distribution. The sample point plotted on the proposed chart corresponds to the largest value among $\left(\left|Z_{1}\right|\right.$, $\left.\left|Z_{2}\right|, \ldots,\left|Z_{p}\right|, W_{1}, W_{2}, \ldots, W_{p}\right), i=1,2, \ldots, p$, where $Z_{i}=\sqrt{n}\left(\bar{X}_{i}-\mu_{i}\right) / \sigma_{i}$ and $W_{i}=k R_{i} / \sigma_{i}$. As the monitoring statistic is the maximum value among standardized sample means and weighted standardized sample ranges, the chart is called the MRMAX chart.

The parameter $k$ is required to attend the imposed condition that, during the in-control period, the statistics $\left(\left|Z_{1}\right|,\left|Z_{2}\right|, \ldots,\left|Z_{p}\right|, W_{1}, W_{2}, \ldots\right.$, $\mathrm{W}_{\mathrm{p}}$ ) have the same probability to exceed $C L$, the control limit of the MRMAX chart.

The process is considered to start with the mean vector and the covariance matrix on target $\left(\mu=\mu_{0}\right.$ and $\left.\Sigma=\Sigma_{0}\right)$, where $\mu_{0}^{\prime}=\left(\mu_{1}, \mu_{2}, \ldots, \mu_{p}\right)$ and $\Sigma_{0}=\left[\begin{array}{cccc}\sigma_{11} & \sigma_{12} & \cdots & \sigma_{1 p} \\ \sigma_{21} & \sigma_{22} & \cdots & \sigma_{2 p} \\ \vdots & \vdots & \cdots & \vdots \\ \sigma_{p 1} & \sigma_{p 2} & \cdots & \sigma_{p p}\end{array}\right]$. The occurrence of the assignable cause changes the mean vector

\begin{tabular}{|c|c|c|c|c|c|c|c|c|c|}
\hline$a$ & $|\delta|$ & $\bar{X} \& S^{2}$ & $\overline{\mathrm{X}} \& R$ & $P V(0)$ & a & $|\delta|$ & $\bar{X} \& S^{2}$ & $\overline{\mathrm{X}} \& R$ & $P V(\%)$ \\
\hline \multirow[t]{6}{*}{1.0} & 0 & 200 & 200 & 0.0 & \multirow[t]{6}{*}{1.5} & 0 & 24.8 & 26.4 & 6.1 \\
\hline & 0.2 & 129.1 & 129.1 & 0.0 & & 0.2 & 21.5 & 22.7 & 5.3 \\
\hline & 0.4 & 52.2 & 52.2 & 0.0 & & 0.4 & 14.8 & 15.3 & 3.3 \\
\hline & 0.6 & 20.5 & 20.5 & 0.0 & & 0.6 & 9.1 & 9.3 & 2.2 \\
\hline & 0.8 & 9.0 & 9.0 & 0.0 & & 0.8 & 5.6 & 5.6 & 0.0 \\
\hline & 1.0 & 4.6 & 4.6 & 0.0 & & 1.0 & 3.6 & 3.6 & 0.0 \\
\hline \multirow[t]{6}{*}{1.2} & 0 & 70.9 & 73.3 & 3.4 & \multirow[t]{6}{*}{2.0} & 0 & 8.8 & 9.5 & 7.4 \\
\hline & 0.2 & 54.3 & 55.7 & 2.6 & & 0.2 & 8.2 & 8.8 & 6.8 \\
\hline & 0.4 & 29.1 & 29.5 & 1.4 & & 0.4 & 6.8 & 7.2 & 5.6 \\
\hline & 0.6 & 14.2 & 14.3 & 0.7 & & 0.6 & 5.2 & 5.4 & 3.7 \\
\hline & 0.8 & 7.3 & 7.3 & 0.0 & & 0.8 & 3.9 & 4.0 & 2.5 \\
\hline & 1.0 & 4.1 & 4.1 & 0.0 & & 1.0 & 2.9 & 2.9 & 0.0 \\
\hline
\end{tabular}

Table 1 . The ARL of the joint charts $(n=5)$. 
from $\mu_{0}^{\prime}$ to $\mu_{1}^{\prime}=\left(\mu_{1}+\delta_{1} \sigma_{1} ; \mu_{2}+\delta_{2} \sigma_{2} ; \ldots\right.$; $\left.\mu_{p}+\delta_{p} \sigma_{p}\right)$ and/or the covariance matrix from $\Sigma_{0}$ to $\Sigma_{1}=\left[\begin{array}{cccc}a_{1} \cdot a_{1} \cdot \sigma_{11} & a_{1} \cdot a_{2} \cdot \sigma_{12} & \cdots & a_{1} \cdot a_{p} \cdot \sigma_{1 p} \\ a_{1} \cdot a_{2} \cdot \sigma_{21} & a_{2} \cdot a_{2} \cdot \sigma_{22} & \cdots & a_{2} \cdot a_{p} \cdot \sigma_{2 p} \\ \vdots & \vdots & \cdots & \vdots \\ a_{1} \cdot a_{p} \cdot \sigma_{p 1} & a_{2} \cdot a_{p} \cdot \sigma_{p 2} & \cdots & a_{p} \cdot a_{p} \cdot \sigma_{p p}\end{array}\right]$. The correlations $\rho_{i j}=\frac{\sigma_{i j}}{\sigma_{i} \sigma_{j}}, i, j=1,2, \ldots, p$, with $\mathrm{i} \neq \mathrm{j}$, are not affected by the assignable cause. After the occurrence of the assignable cause it is assumed that at least one $\left|\delta_{i}\right|$ becomes larger than zero and/or at least one $a_{i}$ becomes larger than one, $\mathrm{i}=1,2, \ldots, p$.

If the MRMAX statistic falls beyond the control limit, $C L$, the control chart signals an out-of-control condition. Once the MRMAX chart signals, the user can immediately examine the sample means or the sample ranges of the $p$ quality characteristics to discover which variable was affected by the assignable cause, that is, the one with the sample mean and/or the sample range larger than the control limit. For security, we might consider that the assignable cause has also affected an other variable when its sample mean and/or sample range is close, even though below the control limit.

\subsubsection{The properties of the MRMAX chart}

Let us consider the bivariate case to illustrate how the properties of the MRMAX chart were obtained, that is, its false alarm risk $\alpha$ and power of detection $P$. We used the property that the sample means are independent of the sample ranges. Therefore, the MRMAX chart has probability $P$ of signaling:

$$
P=P_{M}+P_{D}-P_{M} P_{D}
$$

Regarding to the sample means, the probability $\mathrm{P}_{\mathrm{M}}$ of $\left|\mathrm{Z}_{1}\right|$ and/or $\left|\mathrm{Z}_{2}\right|$ exceeding the control limit is given by:

$$
P_{M}=1-\int_{-C L+\delta_{1} \sqrt{n}}^{C L+\delta_{1} \sqrt{n}} \int_{-C L+\delta_{2} \sqrt{n}}^{C L+\delta_{2} \sqrt{n}} f\left(Z_{1}, Z_{2}\right) d_{Z_{1}} d_{Z_{2}}
$$

where $f\left(Z_{1}, Z_{2}\right)$ is a standardized bivariate normal distribution function, reminding that $C L$ is the control limit of the MRMAX chart. The probability $\mathrm{P}_{\mathrm{M}}$ can be obtained for $p>2$ using an algorithm given in Serel, Moskowitz and Tang (2000).

Regarding to the sample ranges, the probability $\mathrm{P}_{\mathrm{D}}$ of $\mathrm{W}_{1}$ and/or $\mathrm{W}_{2}$ exceeding the control limit is:

$$
P_{D}=1-\operatorname{Pr}\left[\left(W_{1}<C L\right) \cap\left(W_{2}<C L\right)\right]
$$

where $W_{1}=k R_{1} / \sigma_{1}$ and $W_{2}=k R_{2} / \sigma_{2}$, being $R_{i}=\max \left[x_{i 1}\right.$, $\left.x_{i 2}, \ldots, x_{i n}\right]-\min \left[x_{i 1}, x_{i 2}, \ldots, x_{i n}\right], i=1,2$ the sample ranges of two quality characteristics $X_{1}$ and $X_{2}$.
The in-control covariance matrix is given by $\Sigma_{0}=\left(\begin{array}{ll}\sigma_{11} & \sigma_{12} \\ \sigma_{21} & \sigma_{22}\end{array}\right)$. The assignable cause changes the mean vector from $\mu_{0}^{\prime}$ to $\mu_{1}^{\prime}\left(\mu_{1}+\delta_{1} \sigma_{1} ; \mu_{2}+\delta_{2} \sigma_{2}\right)$ and/or changes the covariance matrix from $\Sigma_{0}$ to $\Sigma_{1}=\left(\begin{array}{ll}a_{1} \cdot a_{1} \cdot \sigma_{11} & a_{1} \cdot a_{2} \cdot \sigma_{12} \\ a_{1} \cdot a_{2} \cdot \sigma_{21} & a_{2} \cdot a_{2} \cdot \sigma_{22}\end{array}\right)$. The assignable cause does not affect the correlation between $X_{1}$ and $X_{2}$, given by $\rho=\frac{\sigma_{12}}{\sigma_{1} \sigma_{2}}$. We have that $x_{i} \sim N\left(\mu_{i}, a_{i} \sigma_{i}\right)$, with $\mathrm{i}=1,2$. Then,

$P_{D}=1-F\left(w_{1}, w_{2}\right)$

being $\mathrm{w}_{1}=\mathrm{CL} / \mathrm{a}_{1}$ and $\mathrm{w}_{2}=\mathrm{CL} / \mathrm{a}_{2} . C L$ was divided by $a_{i}$ to hold the condition that $x_{i} / a_{i} \sigma_{i} \sim N\left(\mu_{i} / a_{i} \sigma_{i}, 1\right)$, with $\mathrm{i}=1,2$.

Let $\left(\mathrm{x}_{1}, \mathrm{x}_{2}\right)$ be the pair of values of the two quality characteristics of each inspected item. Consider that $\mathrm{y}_{1}=\min \left(\mathrm{x}_{11}, \mathrm{x}_{12}, \ldots, \mathrm{x}_{1 \mathrm{n}}\right)$ and $\mathrm{y}_{2}=\min \left(\mathrm{x}_{21}, \mathrm{x}_{22}, \ldots, \mathrm{x}_{2 \mathrm{n}}\right)$ and two cases: a) $\left(x_{1 i}=y_{1}, x_{2 i}=y_{2}\right)$, that is, the ith item of the sample has the minimum value of the two quality characteristics; b) $\left(\mathrm{x}_{1 \mathrm{j}}=\mathrm{y}_{1}, \mathrm{x}_{2 \mathrm{j}}>\mathrm{y}_{2}\right)$ and $\left(x_{1 k}>y_{1}, x_{2 k}=y_{2}\right)$ with $j \neq k \in\{1,2, \ldots, n\}$, that is, the jth item of the sample has the minimum value of the first quality characteristic and the kth one has the minimum value of the second quality characteristic. Based on that,

$$
\begin{aligned}
F\left(w_{1}, w_{2}\right) & =n \int_{-\infty}^{\infty} \int_{-\infty}^{\infty} D_{1}^{n-1} d B\left(z_{1}, z_{2}, \rho\right)+ \\
+ & n \int_{-\infty}^{\infty} \int_{-\infty}^{\infty}(n-1) D_{1}^{n-2} D_{2} d G\left(z_{1}, z_{2}\right)
\end{aligned}
$$

where

$B\left(z_{1}, z_{2}, \rho\right)=\frac{1}{2 \pi \sqrt{1-\rho^{2}}} \int_{-\infty}^{y_{1}} \int_{-\infty}^{y_{2}} \exp \left(-\frac{z_{1}^{2}+2 \rho z_{1} z_{2}-z_{2}^{2}}{2\left(1-\rho^{2}\right)}\right) d z_{1} d z_{2}$

and

$G\left(z_{1}, z_{2}\right)=\frac{1}{2 \pi} \int_{-\infty}^{y_{1}} \int_{-\infty}^{y_{2}} \exp \left(-\frac{z_{1}^{2}-z_{2}^{2}}{2}\right) d z_{1} d z_{2}$

The probability $\mathrm{D}_{1}$ is given by:

$$
\begin{aligned}
& D_{1}=\operatorname{Pr}\left[y_{1}<x_{1} \leq y_{1}+w_{1}, y_{2}<x_{2} \leq y_{2}+w_{2}\right] \\
& =B\left(y_{1}+w_{1}, y_{2}+w_{2}, \rho\right)-B\left(y_{1}+w_{1}, y_{2}, \rho\right) \\
& -B\left(y_{1}, y_{2}+w_{2}, \rho\right)-B\left(y_{1}, y_{2}, \rho\right)
\end{aligned}
$$

The probability $\mathrm{D}_{2}$ is given by:

$$
\begin{aligned}
& D_{2}=\operatorname{Pr}\left[y_{1}<x_{1} \leq y_{1}+w_{1} \mid y_{2}\right] \operatorname{Pr}\left[y_{2}<x_{2} \leq y_{2}+w_{2} \mid y_{1}\right] \\
& =\left[\Phi\left(A_{1}\right)-\Phi\left(A_{2}\right)\right]\left[\Phi\left(A_{3}\right)-\Phi\left(A_{4}\right)\right]
\end{aligned}
$$

According to the conditional distribution x|y N(py; $\left.\left(1-\rho^{2}\right)\right)$, see Mood, Graybill and Boes (1974). Then, it follows that: 


$$
\begin{aligned}
& A_{1}=\left(y_{1}+w_{1}-y_{2} \rho\right) / \sqrt{1-\rho^{2}} \\
& A_{2}=\left(y_{1}-y_{2} \rho\right) / \sqrt{1-\rho^{2}} \\
& A_{3}=\left(y_{2}+w_{2}-y_{1} \rho\right) / \sqrt{1-\rho^{2}} \\
& A_{4}=\left(y_{2}-y_{1} \rho\right) / \sqrt{1-\rho^{2}}
\end{aligned}
$$

where $\Phi(\xi)$ is the standard normal cumulative distribution function.

The parameter $k$ is obtained by expression (11), fixing $\alpha_{1}=\alpha_{2}=1$ and $P_{D}=1-\sqrt{1-\alpha}$, recalling that $C L$ is computed by expression (10).

In the Appendix 1 we present the expression to compute $\mathrm{P}_{\mathrm{D}}$ for the trivariate case with good accuracy, once the simulation technique was used only to obtain the probability of a signal given by all standardized sample ranges $W_{1}, W_{2}$ and $W_{3}$ falling beyond the control limit $(C L)$. This probability is small if compared with the probability of a signal given by only one or two standardized sample ranges falling beyond the control limit. Following the calculation presented in the Appendix 1, we can extend the study for the cases where $p>3$.

When the rule of one point in the action region is adopted and the rate of false alarm is specified as $\alpha$. Imposing equal in-control $\mathrm{P}_{\mathrm{D}}$ and $\mathrm{P}_{\mathrm{M}}$ probabilities, the control limit of the MRMAX chart is obtained by expression (10), with $\delta_{1}=\delta_{2}=0$ and $P_{M}=1-\sqrt{1-\alpha}$. The value of $k$ is obtained by expression (12), with $\mathrm{a}_{1}=\mathrm{a}_{2}=1$ and $P_{D}=1-\sqrt{1-\alpha}$. We used the subroutine BNRDF available on the IMSL Fortran library (MICROSOFT..., 1995) to compute the bivariate normal distribution function. The MRMAX chart is not always faster in signaling than the joint $\mathrm{T}^{2}$ and $|\mathrm{S}|$ charts. However, the synthetic procedure, introduced by Wu and Spedding (2000b), improves the performance of the MRMAX chart.

When the synthetic procedure is in use, a second sample point beyond the control limits and not far than $L$ sampling intervals from the first one triggers the alarm, see Figure 1. According to this figure, the number of sampling intervals between the two points beyond $C L$ is $I=3$ and the design parameter $L$ is equal to 5; consequently, the synthetic MRMAX chart signals once $l<L$.

The growing interest in using this rule may be explained by the fact that many practitioners prefer waiting until the occurrence of a second point beyond the control limits before looking for an assignable cause (see $\mathrm{Wu}$ and Spedding (2000a, 2000b), Wu, Zhang and Yeo (2001), Wu, Yeo and Spedding (2001), Calzada and Scariano (2001),

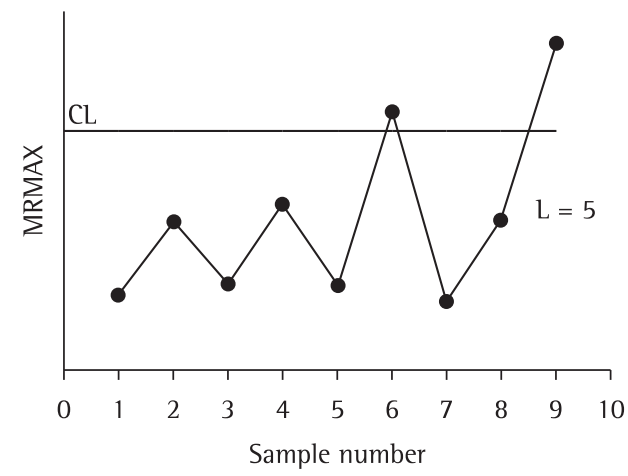

Figure 1 . The synthetic MRMAX chart.

Davis and Woodall (2002), Costa and Rahim (2006), Costa, Magalhães and Epprecht (2008)).

According to Davis and Woodall (2002) the proper parameter to measure the performance of the synthetic chart is the steady-state $A R L$, that is, the $A R L$ value obtained when the process remains in-control for a long time before the occurrence of the assignable cause.

We adopted the following approach to obtain the steady-state $A R L$ for the synthetic MRMAX chart:

Specify $\rho, A R L_{0}, n, L, \alpha_{1}, \alpha_{2}, \delta_{1}$ and $\delta_{2}$;

With $L$ and $A R L_{0}$ find the value of $Q_{0}$ that makes

$\mathrm{s}_{0} \times \mathrm{M} \times \mathbf{1}=\left(1-\sqrt{1-1 / A R L_{0}}\right)^{-1}$

where $\mathrm{M}$ is a matrix of zeros except for $m_{11}=Q_{0}$; $m_{12}=-Q_{0} ; \quad m_{\mathrm{i}, \mathrm{i}+1}=Q_{0}-1, \quad i=2,3, \ldots, L ; \quad$ and $\mathrm{m}_{\mathrm{L+1,1}}=Q_{0}-1 ; 1$ is an $(L+1) \times 1$ vector of ones; and $\mathrm{s}_{0}$ is an $(L+1) \times 1$ vector with $S_{01}=\left[1+(L-1) Q_{0}\right]^{-1}$ and $\mathrm{s}_{0 \mathrm{j}}=Q_{0} s_{01}, j=2, \ldots, L+1$.

With $\delta_{1}=\delta_{2}=0, r, n$ and equation (10) find the value of $C L$ that makes $P_{\mathrm{M}}=1-Q_{0}$;

When the process is out-of-control, the steadystate $A R L$ is given by

$A R L=s_{0}^{\prime} \times M \times 1$

where $\mathrm{M}$ is now a matrix of zeros except for $m_{11}=Q$; $m_{12}=-Q ; m_{\mathrm{i}, i+1}=Q-1, i=2, \ldots, L ;$ and $\mathrm{m}_{\mathrm{L}+1,1}=Q-1$, where $Q=1-P$ with $P$ given by expression (9).

Table 2 shows the influence of the design parameter $L$ on the MRMAX performance. As $L$ increases the speed with which the synthetic MRMAX chart signals also increases. The gain in speed is more significant when $L$ increases from 1 to 6 . For instance, when $\mathrm{a}_{1}=\mathrm{a}_{2}=1$ and $\delta_{1}=\delta_{2}=0.5$, the ARL reduces $18.0 \%$ (from 21.4 to 17.5). On the other hand, as $L$ increases from 6 to 10, the $A R L$ reduces $1.0 \%$ (from 17.5 to 17.3), see Table 2 . 
Table 2. The influence of the $\mathrm{L}$ value on the synthetic MRMAX chart's performance $(\rho=0.5, n=5)$.

\begin{tabular}{|c|c|c|c|c|c|c|c|c|c|c|c|c|c|c|}
\hline & & & & $L=$ & 1 & 2 & 3 & 4 & 5 & 6 & 7 & 8 & 9 & 10 \\
\hline & & & & $C L=$ & 2.350 & 2.469 & 2.536 & 2.582 & 2.617 & 2.644 & 2.667 & 2.687 & 2.703 & 2.719 \\
\hline$a_{1}$ & $a_{2}$ & $\left|\delta_{1}\right|$ & $\left|\delta_{2}\right|$ & \multicolumn{11}{|c|}{$A R L$} \\
\hline \multirow[t]{3}{*}{1.0} & 1.0 & 0 & 0 & & 200.0 & 200.0 & 200.0 & 200.0 & 200.0 & 200.0 & 200.0 & 200.0 & 200.0 & 200.0 \\
\hline & & 0 & 0.5 & & 45.3 & 40.9 & 39.1 & 37.9 & 37.2 & 36.8 & 36.3 & 36.1 & 35.8 & 35.8 \\
\hline & & 0.5 & 0.5 & & 21.4 & 19.2 & 18.4 & 17.9 & 17.7 & 17.5 & 17.4 & 17.3 & 17.3 & 17.3 \\
\hline \multirow[t]{3}{*}{1.25} & 1.25 & 0 & 0 & & 15.4 & 13.6 & 12.9 & 12.5 & 12.3 & 12.1 & 12.1 & 12.0 & 12.0 & 11.9 \\
\hline & & 0 & 0.5 & & 9.67 & 8.43 & 7.98 & 7.74 & 7.60 & 7.5 & 7.5 & 7.4 & 7.4 & 7.4 \\
\hline & & 0.5 & 0.5 & & 6.95 & 6.06 & 5.75 & 5.59 & 5.50 & 5.5 & 5.4 & 5.4 & 5.4 & 5.4 \\
\hline \multirow[t]{4}{*}{1.5} & 1.0 & 0 & 0 & & 9.82 & 8.28 & 7.69 & 7.36 & 7.17 & 7.0 & 7.0 & 6.9 & 6.8 & 6.8 \\
\hline & & 0 & 0.5 & & 7.42 & 6.40 & 6.03 & 5.84 & 5.73 & 5.7 & 5.6 & 5.6 & 5.6 & 5.6 \\
\hline & & 0.5 & 0 & & 7.02 & 5.90 & 5.49 & 5.27 & 5.14 & 5.1 & 5.0 & 5.0 & 4.9 & 4.9 \\
\hline & & 0.5 & 0.5 & & 5.68 & 4.89 & 4.60 & 4.46 & 4.38 & 4.3 & 4.3 & 4.3 & 4.3 & 4.2 \\
\hline
\end{tabular}

\subsection{The MVMAX chart}

Section 5 compares the synthetic MRMAX chart with the synthetic MVMAX chart proposed by Machado, Costa and Marins (2009). The MVMAX statistic is based on the largest value among the standardized sample means (in module) and variances (weighted). For the bivariate case, MVMAX $=\max \left(\left|\mathrm{Z}_{1}\right|,\left|\mathrm{Z}_{2}\right|, \mathrm{W}_{1}, \mathrm{~W}_{2}\right)$, where $\mathrm{Z}_{1}=\sqrt{\mathrm{n}}\left(\overline{\mathrm{X}}_{1}-\mu_{1}\right) / \sigma_{1}, \mathrm{Z}_{2}=\sqrt{\mathrm{n}}\left(\overline{\mathrm{X}}_{2}-\mu_{2}\right) / \sigma_{2}, \mathrm{~W}_{1}=\mathrm{kS}^{2}{ }_{1} l$ $\sigma^{2}, \mathrm{~W}_{2}=\mathrm{kS}^{2}{ }_{2} / \sigma^{2}{ }^{2}, \mathrm{~S}^{2}{ }_{1}=\Sigma_{\mathrm{j}=1}^{\mathrm{n}}\left(\mathrm{x}_{1 \mathrm{j}}-\overline{\mathrm{X}}_{1}\right)^{2} / \mathrm{n}-1$ and $\mathrm{S}_{2}^{2}=\sum_{\mathrm{j}=1}^{\mathrm{n}}\left(\mathrm{x}_{2 \mathrm{j}}-\overline{\mathrm{X}}_{2}\right)^{2} / \mathrm{n}-1$.

The MVMAX chart has also probability $P$ of signaling, reminding that $P=P_{M}+P_{D}-P_{M} P_{D}$. The probability $\mathrm{P}_{M}$ is given by expression (10).

According to Machado, Costa and Marins (2009) the probability $P_{D}$ for the bivariate case is given by:

$$
\begin{gathered}
P_{D}=1-\int_{0}^{\frac{(n-1) C L}{k \alpha_{1}^{2}}} \operatorname{Pr}\left[\chi_{n}^{2}\left(t \rho^{2} / 1-\rho^{2}\right)<\frac{(n-1) C L}{k \alpha_{2}^{2}\left(1-\rho^{2}\right)}\right] \\
\frac{1}{2^{(n-1) / 2} \Gamma[(n-1) / 2]} e^{-t / 2} t^{[(n-1) / 2]-1} d t
\end{gathered}
$$

recalling that the notation $\chi_{n}^{2}(\mathrm{~m})$ represents a non-central chi-square distribution with $n$ degrees of freedom and non-centrality parameter given by $m$. The parameter $k$ is required to attend the imposed condition that, during the in-control period, the standardized sample means and variances have the same probability to exceed $C L$, the control limit of the MVMAX chart.

The approach described in the Appendix 1 can be used to obtain the properties of the multivariate MVMAX chart.

\subsection{The joint $T^{2}$ and /S/ charts}

Section 5 also compares the MRMAX chart with the joint $\mathrm{T}^{2}$ and $|\mathrm{S}|$ charts. The $\mathrm{T}^{2}$ chart was introduced by Hotelling (1947) and it is the most common chart used to control the mean vector of multivariate processes.

Consider that $p$ correlated characteristics are being measured simultaneously and when a sample of size $n$ is taken we have $n$ values of each characteristic and it is possible to calculate the $\bar{X}$ vector, which represents the sample average vector for the $p$ characteristics.

The charting statistic

$$
T^{2}=n\left(\bar{X}-\mu_{0}\right)^{\prime} \sum_{0}^{-1}\left(\bar{X}-\mu_{0}\right)
$$

is called Hotelling's $\mathrm{T}^{2}$ statistic. When the process is in control, $\mathrm{T}^{2}$ is distributed as a chi-square variate with $p$ degrees of freedom, that is, $\mathrm{T}^{2} \sim \chi_{\mathrm{p}}^{2}$. Consequently, the control limit for the $\mathrm{T}^{2}$ chart is $\mathrm{Cl}=\chi_{\mathrm{pa}, \mathrm{a}}^{2}$, where $\alpha$ is the type 1 error. When the process is out-of-control, $\mathrm{T}^{2}$ is distributed as a non-central chi-squared distribution with $p$ degrees of freedom and with non-centrality parameter $\lambda=n\left(\mu-\mu_{0}\right)^{\prime} \Sigma_{0}{ }^{-1}\left(\mu-\mu_{0}\right)$, that is, $T^{2} \sim \chi_{p}^{2}(\lambda)$.

The first multivariate control chart for monitoring the covariance matrix $\Sigma$ was based on the charting statistic obtained from the generalized likelihood ratio test, see Alt (1985). For the case of two variables Alt (1985) proposed the generalized variance $|S|$ statistic to control the covariance matrix $\Sigma$. When the process is in control, $\frac{2 \cdot(n-1) \cdot|\mathbf{S}|^{1 / 2}}{\left|\sum_{0}\right|^{1 / 2}}$ is distributed as a chi-square variable

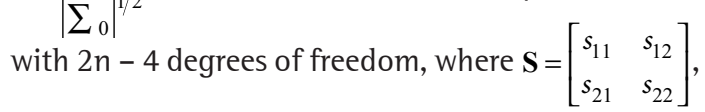
and $S_{11}$ and $S_{22}$ are the sample variances of $X_{1}$ and $\mathrm{X}_{2}$ and $\mathrm{S}_{12}=\mathrm{S}_{21}$ the sample covariances between $\mathrm{X}_{1}$ and $X_{2}$. Consequently, the upper control limit for the $|\mathrm{S}|$ chart is: 
Table 3. Values of $X_{1}, X_{2}, X_{3},\left|Z_{1}\right|,\left|Z_{2}\right|,\left|Z_{3}\right|, W_{1}, W_{2}, W_{3}$, MRMAX, T2 and $|S|$.

\begin{tabular}{|c|c|c|c|c|c|c|c|c|c|c|c|}
\hline \multirow[t]{2}{*}{ Sample } & & \multicolumn{5}{|c|}{ Observations } & \multirow[t]{2}{*}{$|\mathrm{Z}|$} & \multirow[t]{2}{*}{$\mathrm{W}^{*}$} & \multirow[t]{2}{*}{ MRMAX } & \multirow[t]{2}{*}{$\mathrm{T}^{2}$} & \multirow[t]{2}{*}{$|S|$} \\
\hline & & 1 & 2 & 3 & 4 & 5 & & & & & \\
\hline \multirow[t]{3}{*}{1} & $X_{1}$ & 1.973 & 0.584 & -0.819 & 0.213 & 0.667 & 1.171 & 1.595 & 2.124 & 1.386 & 1.024 \\
\hline & $\mathrm{X}_{2}$ & 0.474 & 1.358 & -1.239 & -0.038 & 0.914 & 0.657 & 1.484 & & & \\
\hline & $\mathrm{X}_{3}$ & 0.178 & 2.437 & -0.156 & -1.281 & 0.018 & 0.535 & 2.124 & & & \\
\hline \multirow[t]{3}{*}{2} & & 0.241 & -0.258 & 0.955 & -0.277 & -1.641 & 0.438 & 1.483 & 1.483 & 1.344 & 0.199 \\
\hline & & 1.469 & -0.382 & 1.319 & 0.105 & -0.955 & 0.696 & 1.385 & & & \\
\hline & & 0.621 & -0.385 & 0.854 & 0.422 & -1.666 & 0.069 & 1.440 & & & \\
\hline \multirow[t]{3}{*}{3} & & 1.057 & -1.544 & -1.449 & 0.787 & -0.079 & 0.549 & 1.486 & 1.755 & 3.266 & 0.634 \\
\hline & & 0.083 & -1.977 & -2.396 & 0.171 & 0.195 & 1.755 & 1.480 & & & \\
\hline & & 0.616 & -0.021 & -1.649 & -0.633 & -0.409 & 0.937 & 1.294 & & & \\
\hline \multirow[t]{3}{*}{4} & & 1.712 & 0.404 & -0.219 & -0.374 & 1.377 & 1.297 & 1.192 & 1.547 & 1.854 & 0.184 \\
\hline & & -0.244 & 0.971 & 0.433 & 0.456 & 0.636 & 1.007 & 0.694 & & & \\
\hline & & 0.03 & 1.926 & 1.179 & -0.625 & -0.781 & 0.773 & 1.547 & & & \\
\hline \multirow[t]{3}{*}{5} & & 0.652 & -0.141 & 0.309 & 0.169 & 1.622 & 1.168 & 1.007 & 1.168 & 1.588 & 0.065 \\
\hline & & -0.37 & 0.615 & -0.45 & 0.584 & 1.404 & 0.797 & 1.059 & & & \\
\hline & & 0.839 & -0.927 & 0.428 & -0.437 & 0.824 & 0.325 & 1.009 & & & \\
\hline \multirow[t]{3}{*}{6} & & -2.446 & -1.624 & 0.758 & 0.299 & 0.003 & 1.346 & 1.831 & 2.039 & 4.712 & 1.301 \\
\hline & & 0.296 & -1.003 & 0.988 & 0.911 & 0.600 & 0.801 & 1.138 & & & \\
\hline & & -0.968 & -1.524 & -0.744 & 2.044 & 0.857 & 0.150 & 2.039 & & & \\
\hline \multirow[t]{3}{*}{7} & & 2.112 & -0.505 & 0.852 & -0.047 & 1.704 & 1.841 & 1.495 & 1.868 & 4.598 & 0.016 \\
\hline & & 1.343 & 0.130 & 1.174 & 0.312 & 1.219 & 1.868 & 0.693 & & & \\
\hline & & 0.120 & 0.847 & 0.168 & 0.603 & 0.835 & 1.151 & 0.415 & & & \\
\hline \multirow[t]{3}{*}{8} & & 3.850 & 1.226 & -0.451 & 1.386 & 0.260 & 2.804 & 2.458 & 2.804 & 12.551 & 2.351 \\
\hline & & 0.727 & 0.643 & -0.736 & 0.721 & -1.600 & 0.110 & 1.330 & & & \\
\hline & & 1.401 & -0.782 & 0.958 & 0.400 & -1.350 & 0.280 & 1.572 & & & \\
\hline \multirow[t]{3}{*}{9} & & -0.278 & 1.394 & -1.123 & 0.418 & 1.543 & 0.874 & 1.523 & 1.570 & 1.660 & 0.124 \\
\hline & & -0.791 & 0.830 & 0.225 & 1.956 & 0.343 & 1.146 & 1.570 & & & \\
\hline & & -0.349 & 0.732 & 0.398 & 0.932 & 0.660 & 1.061 & 0.732 & & & \\
\hline \multirow[t]{3}{*}{10} & & -0.105 & 1.548 & -1.388 & 1.266 & 0.079 & 0.626 & 1.678 & 2.564 & 9.869 & 0.094 \\
\hline & & 1.528 & 0.607 & 0.889 & 0.942 & 1.767 & 2.564 & 0.663 & & & \\
\hline & & 0.371 & 1.891 & 1.131 & 0.646 & 1.351 & 2.410 & 0.869 & & & \\
\hline \multirow[t]{3}{*}{11} & & 1.327 & 1.170 & -0.047 & -0.894 & 0.810 & 1.058 & 1.269 & 2.024 & 4.191 & 0.300 \\
\hline & & 0.518 & 1.556 & 1.095 & -0.743 & 0.423 & 1.274 & 1.314 & & & \\
\hline & & -0.033 & 2.522 & 1.369 & 0.280 & 0.388 & 2.024 & 1.460 & & & \\
\hline \multirow[t]{3}{*}{12} & & 0.684 & 1.595 & 1.331 & 1.595 & 1.170 & 2.851 & 1.707 & 2.851 & 8.662 & 0.115 \\
\hline & & 1.864 & -0.545 & -0.434 & -0.462 & 2.443 & 1.282 & 0.521 & & & \\
\hline & & 2.211 & -0.452 & 0.070 & 1.153 & 1.398 & 1.959 & 1.522 & & & \\
\hline \multirow[t]{3}{*}{13} & & 0.169 & 0.946 & -0.865 & 2.077 & -0.260 & 0.924 & 1.681 & 1.818 & 2.252 & 1.151 \\
\hline & & -0.827 & 2.354 & -0.070 & 1.273 & 0.533 & 1.459 & 1.818 & & & \\
\hline & & 0.937 & 0.131 & -0.964 & 0.743 & 1.421 & 1.014 & 1.363 & & & \\
\hline \multirow[t]{3}{*}{14} & & 0.997 & 1.173 & 0.685 & 1.244 & 3.155 & 3.244 & 2.999 & 3.244 & 15.679 & 0.409 \\
\hline & & 0.422 & 0.444 & 0.727 & 0.413 & 1.994 & 1.789 & 0.903 & & & \\
\hline & & -1.841 & 0.258 & 0.500 & -2.094 & 2.798 & 0.169 & 1.207 & & & \\
\hline
\end{tabular}

${ }^{*} \mathrm{k}=0.571$.

$U C L=\frac{\left(\chi_{2 n-4, \alpha}^{2}\right)^{2} \cdot\left|\sum_{0}\right|}{4 \cdot(n-1)^{2}}$

The magnitude of the disturbance is given by $\gamma^{2}$, where $\gamma^{2}=\left|\Sigma_{1}\right| /\left|\Sigma_{0}\right|$. The power of the $|S|$ chart is given by:
$P_{D}=\operatorname{Pr}\left(\chi_{2 n-4}^{2} \geq \frac{\chi_{2 n-4, \alpha}^{2}}{\gamma}\right)$

According to expression (23), any change in the covariance matrix that generates the same $\gamma^{2}$ is detected by the $|S|$ chart with the same power $\left(\mathrm{P}_{\mathrm{D}}\right)$, 
recalling that $A R L=1 / \mathrm{P}_{\mathrm{D}}$, see Aparisi, Jabaloyes and Carrón (2001).

When there are $p$ variables to control, Anderson (2003) gave an expression for the distribution of $|S|$ :

$\frac{(n-1)^{p} \cdot|\mathbf{S}|}{\left|\sum_{0}\right|} \equiv \prod_{i=1}^{p} \chi_{n-1}^{2}$

Aparisi, Jabaloyes and Carrón (1999) obtained the expression to compute the probability density function of $J_{n, p} \equiv \frac{(n-1)^{p} \cdot|\mathbf{S}|}{\left|\sum_{0}\right|}$. Based on $\mathrm{J}_{n, p}$, the upper control limit for the $|S|$ chart is:

$$
U C L=\frac{J_{n, p}^{\alpha} \cdot\left|\sum_{0}\right|}{(n-1)^{p}}
$$

and the chart's power is given by:

$P_{D}=\operatorname{Pr}\left(J_{n, p}>\frac{J_{n, p}^{\alpha}}{\gamma^{2}}\right)$

The drawback of the $\mathrm{T}^{2}$ and the $|\mathrm{S}|$ charts is that, in general, the user is not familiar with the computation of vectors and matrixes.

\section{Illustrative example}

in this section we provide an example to illustrate the ability of the synthetic MRMAX chart and the joint $\mathrm{T}^{2}$ and $|\mathrm{S}|$ charts in detecting shifts in the mean vector and/or in the covariance matrix. To this end, we considered a process with three quality characteristics that follow a trivariate normal distribution. When the process is in-control, the mean vector and the covariance matrix are given by $\mu_{0}=\left(\begin{array}{l}0 \\ 0 \\ 0\end{array}\right), \Sigma_{0}=\left(\begin{array}{lll}1.0 & 0.5 & 0.5 \\ 0.5 & 1.0 & 0.5 \\ 0.5 & 0.5 & 1.0\end{array}\right)$, respectively.

We initially generate 5 samples of size $n=5$ with the process in control. The remaining samples were simulated considering that the assignable cause changed the mean and the variability of $X_{1}$, that is, $\delta_{1}=0.5$ and $\alpha_{1}=1.50$.

Table 3 presents the data of $X_{1}, X_{2}, X_{3},\left|Z_{1}\right|,\left|Z_{2}\right|$, $\left|Z_{3}\right|, W_{1}, W_{2}, W_{3}$, the largest value among $\left(\left|Z_{1}\right|,\left|Z_{2}\right|\right.$, $\left.\left|Z_{3}\right|, W_{1}, W_{2}, W_{3}\right)$, that is, the MRMAX values, $T^{2}$ and $|S|$.

Figure 2 shows the synthetic MRMAX chart with design parameters $L=7$ and $C L=2.777$. The control limit was determined using the algorithm given in Serel, Moskowitz and Tang (2000), with $\delta_{1}=\delta_{2}=\delta_{3}=0$, to assure a false alarm risk $\alpha$ of 0.005 . As the number of sampling intervals $/(=4)$ between the first and the second points beyond the $C L$ is smaller than $L(=7)$, the synthetic MRMAX control chart signals an out-of-control condition at sample 12. We also conclude that the assignable cause affected the $X_{1}$ variable once the sample points beyond the upper control limit correspond to the $\left|\mathrm{Z}_{1}\right|$ values.

Figure 2 shows the joint $\mathrm{T}^{2}$ and $|\mathrm{S}|$ charts. The control limit for the $\mathrm{T}^{2}$ chart is given by $\mathrm{CL}=\chi_{3,0.0025}^{2}=14.320$ and for the $|\mathrm{S}|$ chart is given by expression (24). The joint $\mathrm{T}^{2}$ and $|\mathrm{S}|$ charts signal an out-of-control condition at sample 14. According to Figure 3, the $\mathrm{T}^{2}$ chart was the responsible for the signal; however, it is not possible to identify the variable that had the parameter(s) affected by the assignable cause. The $|\mathrm{S}|$ chart did not give any hint that the assignable cause also increased the variability of $\mathrm{X}_{1}$.

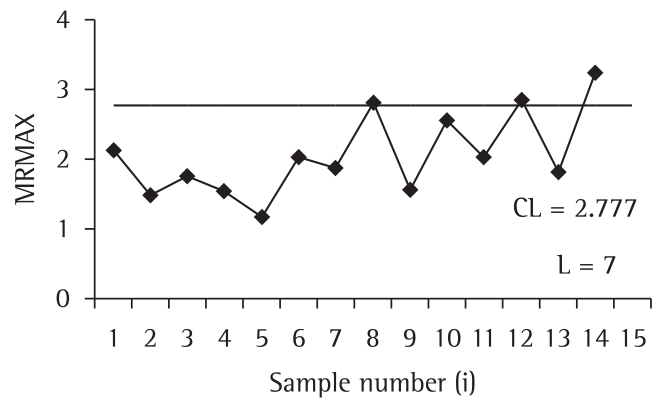

Figure 2. The synthetic MRMAX chart - example.
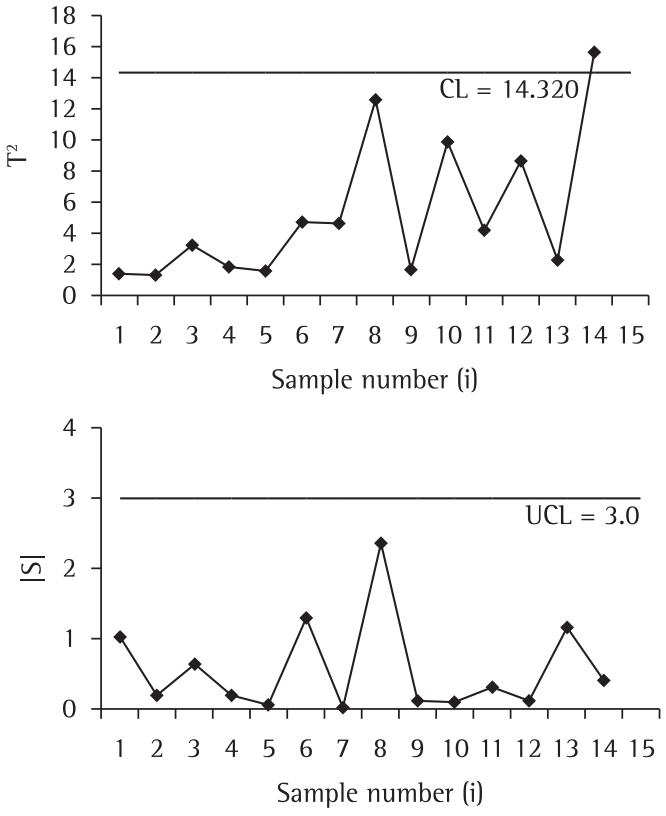

Figure 3. The joint $\mathrm{T}^{2}$ and $|\mathrm{S}|$ charts - example. 


\section{Comparing charts}

In this section we compare the synthetic MRMAX chart with the synthetic MVMAX chart. For the bivariate case, Machado, Costa and Marins (2009) have already compared the synthetic MVMAX chart with the joint $\mathrm{T}^{2}$ and $|\mathrm{S}|$ charts and it is, in general, faster in signaling, except when the correlation between the two variables is high.

Table 4 presents the steady-state ARLs for the synthetic MVMAX and MRMAX charts, where $\rho=0.0 ; 0.5 ; 0.7, \mathrm{a}_{1}$ and $\mathrm{a}_{2}=1.0 ; 1.25 ; 1.5$ and $\delta_{1}$ and $\delta_{2}=0.0 ; 0.5 ; 0.75 ; 1.0$. A type 1 risk of $0.5 \%$

Table 4. Steady-state ARL values of the synthetic MVMAX and MRMAX charts. ( $n=5$ and $\mathrm{L}=7$ ).

\begin{tabular}{|c|c|c|c|c|c|c|c|c|c|c|c|c|c|c|c|}
\hline \multirow{2}{*}{\multicolumn{2}{|c|}{$\begin{array}{c}\text { Shifts } \\
\text { (covariance } \\
\text { matrix) }\end{array}$}} & \multirow[b]{3}{*}{$\rho$} & \multicolumn{13}{|c|}{ Shifts (mean vector) } \\
\hline & & & \multirow{2}{*}{$\begin{array}{l}\left|\delta_{1}\right| \\
\left|\delta_{2}\right| \\
\end{array}$} & \multirow{2}{*}{$\begin{array}{l}0 \\
0\end{array}$} & \multirow{2}{*}{$\begin{array}{c}0 \\
0.5 \\
\end{array}$} & \multirow{2}{*}{$\begin{array}{c}0.5 \\
0 \\
\end{array}$} & \multirow{2}{*}{$\begin{array}{l}0.5 \\
0.5 \\
\end{array}$} & \multirow{2}{*}{$\begin{array}{c}0 \\
0.75 \\
\end{array}$} & \multirow{2}{*}{$\begin{array}{c}0.75 \\
0 \\
\end{array}$} & \multirow{2}{*}{$\begin{array}{l}0.5 \\
0.75 \\
\end{array}$} & \multirow{2}{*}{$\begin{array}{r}0.75 \\
0.5 \\
\end{array}$} & \multirow{2}{*}{$\begin{array}{l}0.75 \\
0.75 \\
\end{array}$} & \multirow{2}{*}{$\begin{array}{c}0 \\
1.0 \\
\end{array}$} & \multirow{2}{*}{$\begin{array}{c}1.0 \\
0 \\
\end{array}$} & \multirow{2}{*}{$\begin{array}{l}1.0 \\
1.0 \\
\end{array}$} \\
\hline$a_{1}$ & $a_{2}$ & & & & & & & & & & & & & & \\
\hline \multirow[t]{6}{*}{1.0} & 1.0 & 0.0 & & 200.0 & $36.3^{*}$ & 36.3 & 17.4 & 10.8 & 10.8 & 7.9 & 7.9 & 5.1 & 4.3 & 4.3 & 2.3 \\
\hline & & & & 200.0 & $36.3^{* *}$ & 36.3 & 17.4 & 10.8 & 10.8 & 7.9 & 7.9 & 5.1 & 4.3 & 4.3 & 2.3 \\
\hline & & 0.5 & & 200.0 & $36.3^{*}$ & 36.3 & 17.4 & 10.8 & 10.8 & 7.9 & 7.9 & 5.1 & 4.3 & 4.3 & 2.3 \\
\hline & & & & 200.0 & $36.3^{* *}$ & 36.3 & 17.4 & 10.8 & 10.8 & 7.9 & 7.9 & 5.1 & 4.3 & 4.3 & 2.3 \\
\hline & & 0.7 & & 200.0 & $36.3^{*}$ & 36.3 & 17.4 & 10.8 & 10.8 & 7.9 & 7.9 & 5.1 & 4.3 & 4.3 & 2.3 \\
\hline & & & & 200.0 & $36.3^{* *}$ & 36.3 & 17.4 & 10.8 & 10.8 & 7.9 & 7.9 & 5.1 & 4.3 & 4.3 & 2.3 \\
\hline \multirow[t]{6}{*}{1.25} & 1.0 & 0.0 & & 25.1 & 14.0 & 11.4 & 8.2 & 7.1 & 6.0 & 5.2 & 5.0 & 3.8 & 3.6 & 3.4 & 2.1 \\
\hline & & & & 28.2 & 15.0 & 12.1 & 8.6 & 7.3 & 6.2 & 5.4 & 5.1 & 3.8 & 3.7 & 3.5 & 2.1 \\
\hline & & 0.5 & & 25.2 & 14.0 & 11.4 & 8.2 & 7.1 & 6.0 & 5.2 & 5.0 & 3.8 & 3.6 & 3.4 & 2.1 \\
\hline & & & & 26.5 & 14.4 & 11.7 & 8.4 & 7.2 & 6.1 & 5.3 & 5.1 & 3.8 & 3.6 & 3.5 & 2.1 \\
\hline & & 0.7 & & 25.0 & 14.0 & 11.4 & 8.2 & 7.1 & 6.0 & 5.2 & 5.0 & 3.8 & 3.6 & 3.4 & 2.1 \\
\hline & & & & 25.1 & 14.0 & 11.4 & 8.2 & 7.1 & 6.0 & 5.2 & 5.0 & 3.8 & 3.6 & 3.6 & 2.1 \\
\hline \multirow[t]{6}{*}{1.5} & 1.0 & 0.0 & & 7.0 & 5.6 & 5.0 & 4.3 & 4.1 & 3.7 & 3.4 & 3.3 & 2.8 & 2.7 & 2.7 & 1.9 \\
\hline & & & & 7.5 & 5.9 & 5.2 & 4.5 & 4.2 & 3.8 & 3.5 & 3.4 & 3.8 & 2.8 & 2.7 & 1.9 \\
\hline & & 0.5 & & 7.0 & 5.6 & 5.0 & 4.3 & 4.1 & 3.7 & 3.4 & 3.3 & 2.8 & 2.7 & 2.7 & 1.9 \\
\hline & & & & 7.1 & 5.7 & 5.0 & 4.3 & 4.1 & 3.7 & 3.4 & 3.3 & 2.8 & 2.7 & 2.7 & 1.9 \\
\hline & & 0.7 & & 6.9 & 5.6 & 5.0 & 4.3 & 4.1 & 3.7 & 3.4 & 3.3 & 2.8 & 2.7 & 2.7 & 1.9 \\
\hline & & & & 6.7 & 5.5 & 4.9 & 4.2 & 4.0 & 3.6 & 3.3 & 3.3 & 2.7 & 2.7 & 2.6 & 1.9 \\
\hline \multirow[t]{6}{*}{1.25} & 1.25 & 0.0 & & 11.6 & 7.3 & 7.3 & 5.3 & 4.7 & 4.7 & 3.8 & 3.8 & 3.0 & 3.0 & 3.0 & 1.9 \\
\hline & & & & 10.2 & 6.7 & 6.7 & 5.0 & 4.4 & 4.4 & 3.7 & 3.7 & 2.9 & 2.9 & 2.9 & 1.9 \\
\hline & & 0.5 & & 12.1 & 7.5 & 7.5 & 5.4 & 4.7 & 4.7 & 3.9 & 3.9 & 3.1 & 3.0 & 3.0 & 2.0 \\
\hline & & & & 10.6 & 6.9 & 6.9 & 5.1 & 4.5 & 4.5 & 3.7 & 3.7 & 3.0 & 2.9 & 2.9 & 1.9 \\
\hline & & 0.7 & & 12.5 & 7.7 & 7.7 & 5.5 & 4.8 & 4.8 & 3.9 & 3.9 & 3.1 & 3.1 & 3.1 & 2.0 \\
\hline & & & & 11.2 & 7.2 & 7.2 & 5.3 & 4.6 & 4.6 & 3.8 & 3.8 & 3.0 & 3.0 & 3.0 & 1.9 \\
\hline \multirow[t]{6}{*}{1.25} & 1.5 & 0.0 & & 5.2 & 4.1 & 4.2 & 3.4 & 3.2 & 3.2 & 2.8 & 2.8 & 2.4 & 2.4 & 2.4 & 1.8 \\
\hline & & & & 4.1 & 3.4 & 3.5 & 3.0 & 2.8 & 2.8 & 2.5 & 2.5 & 2.2 & 2.2 & 2.2 & 1.7 \\
\hline & & 0.5 & & 5.4 & 4.2 & 4.3 & 3.5 & 3.2 & 3.3 & 2.8 & 2.8 & 2.4 & 2.5 & 2.4 & 1.8 \\
\hline & & & & 4.3 & 3.5 & 3.6 & 3.1 & 2.9 & 2.9 & 2.6 & 2.6 & 2.2 & 2.3 & 2.3 & 1.7 \\
\hline & & 0.7 & & 5.5 & 4.2 & 4.4 & 3.5 & 3.3 & 3.3 & 2.9 & 2.9 & 2.4 & 2.5 & 2.5 & 1.8 \\
\hline & & & & 4.7 & 3.7 & 3.8 & 3.2 & 3.0 & 3.0 & 2.7 & 2.7 & 2.3 & 2.3 & 2.3 & 1.7 \\
\hline \multirow[t]{6}{*}{1.5} & 1.5 & 0.0 & & 3.4 & 2.9 & 2.9 & 2.6 & 2.5 & 2.5 & 2.3 & 2.3 & 2.0 & 2.1 & 2.1 & 1.6 \\
\hline & & & & 3.0 & 2.6 & 2.6 & 2.4 & 2.3 & 2.3 & 2.1 & 2.1 & 1.9 & 1.9 & 1.9 & 1.6 \\
\hline & & 0.5 & & 3.6 & 3.1 & 3.1 & 2.7 & 2.6 & 2.6 & 2.3 & 2.3 & 2.1 & 2.1 & 2.1 & 1.6 \\
\hline & & & & 3.2 & 2.8 & 2.8 & 2.5 & 2.4 & 2.4 & 2.2 & 2.2 & 2.0 & 2.0 & 2.0 & 1.6 \\
\hline & & 0.7 & & 3.8 & 3.2 & 3.2 & 2.8 & 2.6 & 2.6 & 2.4 & 2.4 & 2.1 & 2.2 & 2.2 & 1.7 \\
\hline & & & & 3.4 & 2.9 & 2.9 & 2.6 & 2.5 & 2.5 & 2.3 & 2.3 & 2.0 & 2.0 & 2.0 & 1.6 \\
\hline
\end{tabular}


Table 5. ARL values of the synthetic MRMAX chart and the joint $\mathrm{T}^{2}$ and the $|\mathrm{S}|$ charts $(\mathrm{n}=5 ; \rho=0.5$ and $\mathrm{L}=7)$.

\begin{tabular}{|c|c|c|c|c|c|c|c|c|c|c|c|}
\hline \multirow{3}{*}{\multicolumn{3}{|c|}{$\begin{array}{c}\text { Shifts } \\
\text { (covariance matrix) }\end{array}$}} & \multicolumn{9}{|c|}{ Shifts (mean vector) } \\
\hline & & & \multirow{2}{*}{$\frac{\left|\delta_{1}\right|}{\left|\delta_{2}\right|}$} & \multirow{3}{*}{$\begin{array}{l}0 \\
0 \\
0\end{array}$} & \multirow{3}{*}{$\begin{array}{c}0 \\
0.5 \\
0\end{array}$} & \multirow{3}{*}{$\begin{array}{c}0 \\
0 \\
0.5\end{array}$} & \multirow{3}{*}{$\begin{array}{c}0.5 \\
0 \\
0\end{array}$} & \multirow{2}{*}{$\begin{array}{l}0.5 \\
0.5 \\
\end{array}$} & \multirow{2}{*}{$\begin{array}{c}0.5 \\
0 \\
\end{array}$} & \multirow{2}{*}{$\begin{array}{l}0.0 \\
0.5 \\
\end{array}$} & \multirow{2}{*}{$\begin{array}{l}0.5 \\
0.5 \\
\end{array}$} \\
\hline & & & & & & & & & & & \\
\hline$a_{1}$ & $a_{2}$ & $a_{3}$ & $\left|\delta_{3}\right|$ & & & & & 0 & 0.5 & 0.5 & 0.5 \\
\hline \multirow{2}{*}{1.0} & 1.0 & 1.0 & & $200.0^{*}$ & 38.3 & 38.3 & 38.3 & 25.8 & 25.8 & 25.8 & 37.9 \\
\hline & & & & $200.0^{* *}$ & 46.2 & 46.2 & 46.2 & 25.4 & 25.4 & 25.4 & 17.9 \\
\hline \multirow[t]{2}{*}{1.25} & 1.0 & 1.0 & & 57.6 & 21.5 & 21.5 & 17.0 & 14.1 & 14.1 & 16.1 & 19.7 \\
\hline & & & & 32.6 & 18.8 & 18.8 & 14.2 & 11.3 & 11.3 & 13.7 & 9.58 \\
\hline \multirow[t]{2}{*}{1.25} & 1.25 & 1.0 & & 25.7 & 11.6 & 13.4 & 11.6 & 9.15 & 9.96 & 9.96 & 12.0 \\
\hline & & & & 16.1 & 9.58 & 11.6 & 9.58 & 7.30 & 8.11 & 8.11 & 6.62 \\
\hline \multirow[t]{2}{*}{1.25} & 1.25 & 1.25 & & 13.7 & 8.0 & 8.0 & 8.0 & 6.78 & 6.78 & 6.78 & 7.87 \\
\hline & & & & 10.6 & 7.3 & 7.3 & 7.3 & 5.93 & 5.93 & 5.93 & 5.19 \\
\hline
\end{tabular}

${ }^{*}$ Joint $\mathrm{T}^{2}$ and the $|\mathrm{S}|$ charts; **MRMAX chart.

is adopted. If it is well known that the assignable cause only affects the variability of one variable at a time, then the synthetic MRMAX chart is, in general, the best option. In the other cases, the MVMAX chart is, in general, faster in signaling than the MRMAX chart. However, even in these cases, the steady-state $A R L$ reduction provided by the MVMAX chart is very small. For the case where the assignable cause does not affect the dispersion of the process, the MVMAX and MRMAX charts have the same performance for any shift in the mean vector. The correlation between the two variables has minor influence on the performance of both charts.

For the multivariate case, the comparison between the synthetic MVMAX and MRMAX charts led to the same conclusions.

Table 4 was built considering three different values of $a_{1}$ and $a_{2}$ and four different values of $\delta_{1}$ and $\delta_{2}$. The orthogonal array is, in this case, made up of 144 combinations; however, these tables present only one half of the orthogonal array. The explanation is that the symmetric cases $\left(a_{1}=c_{1}\right.$, $\mathrm{a}_{2}=\mathrm{c}_{2}, \delta_{1}=\mathrm{c}_{3}$ and $\left.\delta_{2}=\mathrm{c}_{4}\right)$ and $\left(\mathrm{a}_{1}=\mathrm{c}_{2}, \mathrm{a}_{2}=\mathrm{c}_{1}\right.$, $\delta_{1}=c_{4}$ and $\delta_{2}=c_{3}$ ), with $c_{1}, c_{2} \in\{1,1.25,1.5\}$ and $c_{3}, c_{4} \in\{0,0.5,0.75,1.0\}$, lead to the same steady-state $A R L$.

We also compare the synthetic MRMAX chart with the joint $\mathrm{T}^{2}$ and the $|\mathrm{S}|$ charts. Table 5 presents the ARLs for the joint $\mathrm{T}^{2}$ and the $|\mathrm{S}|$ charts and the synthetic MRMAX chart, considering the trivariate case. The synthetic MRMAX chart is, in general, faster in signaling than the joint $\mathrm{T}^{2}$ and the $|\mathrm{S}|$ charts, except in the case where the assignable cause affects the mean of only one variable at a time and does not affect the covariance matrix. The same is observed when $\rho_{12} \neq \rho_{13}$.
We did not consider the joint $\mathrm{T}^{2}$ and the $|\mathrm{S}|$ charts based on the synthetic procedure, because it is not simple to deal with two charts and the rule of two points in the action region.

\section{Conclusions}

In this article we proposed a new chart for monitoring the mean vector and the covariance matrix of multivariate processes. The monitoring statistic associated to the MRMAX chart is based on the sample means and sample ranges. As the practitioners are, in general, more familiar with means and ranges, they will not have difficult to use the proposed chart. In terms of efficiency, we can say that, for the bivariate case, the MRMAX chart and the MVMAX chart, which is based on sample means and sample variances, have similar performance. This result differs from the univariate case, where the joint $\bar{X}$ and $R$ charts are slightly slower than the joint $\bar{X}$ and $S^{2}$ charts in signaling.

An interesting extension of this work is the development of a practical procedure to design the MRMAX chart considering $\alpha, p$ and $n$ as input parameters.

\section{References}

ALT, F. B. Multivariate quality control. In: KOTZ, S.; JOHNSON, N. L. (Ed.). Encyclopedia of Statistical Sciences. Wiley, 1985.

ANDERSON, T. W. An introduction to multivariate statistical analysis. Stanford: John Wiley, 2003.

APARISI, F.; JABALOYES, J.; CARRIÓN, A. Statistical properties of the $|\mathrm{S}|$ multivariate control chart. Communication in Statistics - Theory and Methods, v. 28, p. 2671-2686, 1999.

APARISI, F.; JABALOYES, J.; CARRIÓN, A. Generalized variance chart design with adaptive sample sizes. The 
bivariate case. Communication in Statistics - Simulation and Computation, v. 30, p. 931-948, 2001.

CALZADA, M. E.; SCARIANO, S. M. The robustness of the synthetic control chart to non-normality. Communications in Statistics: Simulation and Computation, v. 30, p. 311-326, 2001.

CHEN, G.; CHENG, S. W.; XIE, H. A new multivariate control chart for monitoring both location and dispersion. Communications in Statistics-Simulation and Computation, v. 34, p. 203-217, 2005.

CHOU, C. Y. et al. Economic-statistical design of multivariate control charts using quality loss function. International Journal of Advanced Manufacturing Technology, v. 20, p. 916-924, 2002.

COSTA, A. F. B.; MACHADO, M. A. G. Synthetic control chart with two-stage sampling for monitoring bivariate processes. Pesquisa Operacional, v. 27, p. 117-130, 2007.

COSTA, A. F. B.; MACHADO, M. A. G. A new chart for monitoring the covariance matrix of bivariate processes. Communications in Statistics - Simulation and Computation, v. 37, p. 1453-1465, 2008a.

COSTA, A. F. B.; MACHADO, M. A. G. Bivariate control charts with double sampling. Journal of Applied Statistics, v. 35 , p. $809-822$, 2008 b.

COSTA, A. F. B.; MACHADO, M. A. G. A new chart based on the sample variances for monitoring the covariance matrix of multivariate processes. International Journal of Advanced Manufacturing Technology, v. 41, p. 770-779, 2009.

COSTA, A. F. B.; RAHIM, M. A. A synthetic control chart for monitoring the process mean and variance. Journal of Quality In Maintenance Engineering, v. 12, p. 81-88, 2006.

COSTA, A. F. B.; EPPRECHT E. K.; CARPINETTI, L. C. R. Controle estatístico de qualidade. 2. ed. São Paulo: Atlas, 2005. 334 p.

COSTA, A. F. B.; DE MAGALHÃES, M. S; EPPRECHT, E. K. Monitoring the process mean and variance using synthetic control chart with two-stage testing. International Journal of Production Research, http://dx.doi.org/10.1080/00207540802047098, 2008.

DAVIS, R. B.; WOODALL, W. H. Evaluating and improving the synthetic control chart. Journal of Quality Technology, v. 34, p. 200-208, 2002.

HOTELLING, H. Multivariate quality control, illustrated by the air testing of sample bombsights. Techniques of Statistical Analysis. New York: McGraw Hill, 1947. p. 111-184.

KHOO, M. B. C. A new bivariate control chart to monitor the multivariate process mean and variance simultaneously. Quality Engineering, v. 17, p. 109-118, 2005.

MACHADO, M. A. G; COSTA, A. F. B. The double sampling and the EWMA charts based on the sample variances. International Journal of Production Economics, v. 114, p. 134-148, 2008a.

MACHADO, M. A. G; COSTA, A. F. B. The use of principal components and simultaneous univariate charts to control multivariate processes. Pesquisa Operacional, v. 28, p. $173-196,2008$ b.

MACHADO, M. A. G.; DE MAGALHÃES, M. S; COSTA, A. F. B. Gráfico de controle de VMAX para o monitoramento da matriz de covariâncias. Revista Produção, v. 18, p. 222-239, 2008.

MACHADO, M. A. G.; COSTA, A. F. B.; RAHIM, M. A. The synthetic control chart based on two sample variances for monitoring the covariance matrix. Quality and Reliability Engineering International, v. 25, p. 595-606, 2008.

MACHADO, M. A. G.; COSTA, A. F. B.; MARINS, F. A. S. Control charts for monitoring the mean vector and the covariance matrix of bivariate processes. International Journal of Advanced Manufacturing Technology, v. 45, p. 772-785, 2009.

MACHADO, M. A. G.; COSTA, A. F. B.; ClARO, F. A. E. Monitoring bivariate processes. Pesquisa Operacional, v. 29, p. 547-562, 2009.

MICROSOFT FORTRAN POWER STATION 4.0. Professional edition with Microsoft IMSL Mathematical and Statistical Libraries, Microsoft Corporation, 1995.

MOOD, A. M.; GRAYBILL, F. A.; BOES, D. C Introduction to the theory of statistics. McGraw-Hill, 1974.

TAKEMOTO, Y.; ARIZONO, I. A study of multivariate $(\bar{X}, S)$ control chart based on Kullback-Leibler information. International Journal of Advanced Manufacturing Technology, v. 25, p. 1205-1210, 2005.

SEREL, D. A.; MOSKOWITZ, H.; TANG, J. Univariate $\bar{X}$ control charts for individual characteristics in a multinormal model. IIE Transactions, v. 32, p. 1115-1125, 2000.

WU, Z.; SPEDDING, T. A. Implementing synthetic control charts. Journal of Quality Technology, v. 32, p. 75-78, 2000a.

WU, Z.; SPEDDING, T. A. A synthetic control chart for detecting small shifts in the process mean. Journal of Quality Technology, v. 32, p. 32-38, 2000b.

WU, Z.; YEO, S. H.; SPEDDING, T. A. A synthetic control chart for detecting fraction nonconforming increases. Journal of Quality Technology, v. 33, p. 104-111, 2001.

WU, Z.; ZHANG, X.; YEO, S. H. Design of sum-ofconforming-run-length control charts. European Journal of Operational research, v. 132, p. 187-196, 2001.

ZHANG, G.; CHANG, S. 1. Multivariate EWMA control charts using individual observations for process mean and variance monitoring and diagnosis. International Journal of Production Research, v. 46, p. 6855-6881, 2008.

\section{Acknowledgements}

This work was supported by CNPq - National Council for Scientific and Technological Development, Project 307744/2006-0 - and FAPESP - The State of São Paulo Research Foundation, Project 2008/09922-0. We would like to thank the two anonymous referees who carefully read an earlier draft and made many constructive suggestions and Professor Philippe Castagliola, the organizer of the First International Symposium on Statistical Process Control (ISSPC 2009) that was held in Nantes, France, on July 16-17, 2009. 


\section{Monitoramento do vetor de médias e da matriz de covariâncias de processos multivariados baseado nas médias e nas amplitudes amostrais}

\section{Resumo}

Os gráficos conjuntos de $\bar{X}$ e $R$ e $\bar{X}$ e $S^{2}$ são os mais utilizados para o monitoramento da média e da dispersão do processo. Com os tamanhos de amostra usuais de 4 e 5 , os gráficos de $\bar{X}$ e $R$ em uso conjunto são ligeiramente inferior aos gráficos de $\bar{X}$ e $S^{2}$ em uso conjunto em termos da eficiência em detectar alterações no processo. Neste artigo, mostra-se que para o caso multivariado, os gráficos baseados nas médias amostrais padronizadas e amplitudes amostrais (gráfico MRMAX) ou nas médias amostrais padronizadas e variâncias amostrais (gráfico MVMAX) são similares em termos da eficiência em detectar alterações no vetor de médias e/ou na matriz de covariâncias. A familiaridade do usuário com o cálculo de amplitudes amostrais é um aspecto favorável do gráfico MRMAX. Um exemplo é apresentado para ilustrar a aplicação do gráfico proposto.

\section{Palavras-chave}

Gráficos de controle. Vetor de médias. Matriz de covariância. Processos multivariados.

Appendix 1. The probability $\mathrm{p}_{\mathrm{D}}$ of the MRMAX chart - the trivariate case.

Consider the statistics $W_{1}=k_{1} / \sigma_{1}, W_{2}=k_{2} / \sigma_{2}$ and $W_{3}=k R_{3} / \sigma_{3}$ where $R_{i}=\max \left[x_{i 1}, x_{i 2}, \ldots, x_{i n}\right]-$ $\min \left[\mathrm{x}_{\mathrm{i} 1}, \mathrm{x}_{\mathrm{i} 2}, \ldots, \mathrm{x}_{\mathrm{in}}\right], \mathrm{i}=1,2,3$ are the sample ranges of three quality characteristics $\mathrm{X}_{1}, \mathrm{X}_{2}$ and $\mathrm{X}_{3}$. Then,

$$
P_{D}=1-\operatorname{Pr}\left[\left(W_{1}<C L\right) \cap\left(W_{2}<C L\right) \cap\left(W_{3}<C L\right)\right]
$$

The in-control covariance matrix is given by $\Sigma_{0}=\left(\begin{array}{lll}\sigma_{11} & \sigma_{12} & \sigma_{13} \\ \sigma_{21} & \sigma_{22} & \sigma_{23} \\ \sigma_{31} & \sigma_{32} & \sigma_{33}\end{array}\right)$. The assignable cause changes the mean vector from $\mu_{0}^{\prime}$ to $\mu_{1}^{\prime}=\left(\mu_{1}+\delta_{1} \sigma_{1} ; \mu_{2}+\delta_{2} \sigma_{2} ; \mu_{3}+\delta_{3} \sigma_{3}\right)$ and/or changes the covariance matrix from $\Sigma_{0}$ to $\Sigma_{1}=\left(\begin{array}{lll}a_{1} \cdot a_{1} \cdot \sigma_{11} & a_{1} \cdot a_{2} \cdot \sigma_{12} & a_{1} \cdot a_{3} \cdot \sigma_{13} \\ a_{1} \cdot a_{2} \cdot \sigma_{21} & a_{2} \cdot a_{2} \cdot \sigma_{22} & a_{2} \cdot a_{3} \cdot \sigma_{23} \\ a_{1} \cdot a_{3} \cdot \sigma_{31} & a_{2} \cdot a_{3} \cdot \sigma_{23} & a_{3} \cdot a_{3} \cdot \sigma_{33}\end{array}\right)$, where $\rho_{i j}=\frac{\sigma_{i j}}{\sigma_{i} \sigma_{j}}, \mathrm{i} \neq \mathrm{j} \in\{1,2,3\}, \sigma_{\mathrm{ij}}=\sigma_{\mathrm{ji}}, \mathrm{a}_{\mathrm{k}}>1, \mathrm{k} \in\{1,2,3\}$ and $a_{i} \geq 1, i \neq k \in\{1,2,3\}$. Then we have

$$
P_{D}=1-F\left(w_{1}, w_{2}, w_{3}\right)
$$

being $\mathrm{w}_{\mathrm{i}}=\mathrm{CL} / \mathrm{a}_{\mathrm{i}}, \mathrm{i}=1,2,3$.

If $A, B$ and $C$ are the events of $\mathrm{W}_{\mathrm{i}}<\mathrm{CL}, \mathrm{i}=1,2,3$, respectively, then the probability $\mathrm{P}_{\mathrm{D}}$ is given by:

$$
P_{D}=1-\operatorname{Pr}(A \cap B \cap C)
$$

that is

$$
P_{D}=\operatorname{Pr}(A)+\operatorname{Pr}(B)+\operatorname{Pr}(C)-\operatorname{Pr}(A \cap B)-\operatorname{Pr}(A \cap C)-\operatorname{Pr}(B \cap C)+\operatorname{Pr}(\bar{A} \cap \bar{B} \cap \bar{C})
$$

where the probabilities $\operatorname{Pr}(\mathrm{A}), \operatorname{Pr}(\mathrm{B})$ and $\operatorname{Pr}(\mathrm{C})$ are computed by expression (7) from Section 2.1; the probabilities $\operatorname{Pr}(A \cap B), \operatorname{Pr}(A \cap C)$ and $\operatorname{Pr}(B \cap C)$ are computed by expression (11) and the probability $\operatorname{Pr}(\overline{\mathrm{A}} \cap \overline{\mathrm{B}} \cap \overline{\mathrm{C}})$ is obtained by simulation. This proposed way to compute (A3) allowed us to obtain the probability $P_{D}$ with good accuracy, once the probability of all samples ranges $R_{1}, R_{2}$ and $R_{3}$ falling beyond the $C L$, is small if compared with the $P_{D}$ value.

We compared the $P_{D}$ values given by expression (A3), where the simulation technique was used only to compute $\operatorname{Pr}(\overline{\mathrm{A}} \cap \overline{\mathrm{B}} \cap \overline{\mathrm{C}})$, with the $\mathrm{P}_{\mathrm{D}}$ values given by expression (A2) obtained by pure simulation. We found that the results obtained by (A3) are much more precise than the ones obtained by (A2). Following the development proposed in this Appendix, we can extend the study for the cases where $p>3$. 